General paper

\title{
EVALUATION OF BENDING STRENGTH AFFECTED BY SPECIMEN GEOMETRY IN SILICON NITRIDE
}

\author{
Toshihiko HosHide, Hirokazu SANO and Hiroyuki HoNDA \\ Department of Energy Conversion Science, \\ Faculty of Energy Science, Kyoto University, \\ Sakyo-ku, Kyoto 606-01, Japan
}

\begin{abstract}
Four-point bending tests of a gas pressure sintered silicon nitride were conducted using notched specimens with different notch shapes as well as smooth specimens of distinct sizes, and the effect of the specimen geometry on the bending strength was experimentally clarified. The mean strength in smooth specimens could be almost correlated with the effective volume, though the mean strength in notched specimens shifted toward the lower strength side compared with the relation for smooth specimens. From observation of fracture surface, no unique correlation of the strength with the effective volume was suggested to be ascribed to a difference in flaw morphology between smooth and notched specimens. To discuss the efficiency of the effective volume, a Monte Carlo simulation was also carried out by assuming the same distribution characteristics of cracks in a material. The simulated result revealed that the effect of the specimen geometry on the strength was explained by using the effective volume. The effective volume, however, was found to be inefficient because of a failure of the primitive assumption in the Weibull theory when the flaw density was extremely low in a material.
\end{abstract}

Key words: Ceramic strength, Size effect, Notched component, Effective volume, Four-point bending, Monte Carlo simulation, Statistical approach, Silicon nitride

\section{INTRODUCTION}

It has been reported that the shape and/or size of specimen and the loading mode affect strength characteristics in ceramic materials [1-12]. For successful applications of ceramics to engineering components, strength characteristics of notched components with an appropriate procedure to estimate them should be also investigated in the relation to the well-known size effect [13].

The effective volume proposed by Davies [13], as one of candidate design parameters, has been applied to evaluate the size effect on strength in ceramics [14]. It should be noted, however, that there may be a limitation of the applicability of the effective volume to the strength assessment, which is associated with the assumption made in deriving the parameter from the Weibull theory [15]. This problem has never been discussed.

In the present work, four-point bending tests of a silicon nitride, superior one of current structural ceramics, were conducted using notched specimens with different notch shapes and also smooth specimens of distinct sizes. The influence of size and/or notch shape of specimen on the bending strength was experimentally clarified. The applicability of the effective volume to the size effect on strength was discussed by a Monte Carlo simulation in addition to the experimental result.

\section{STRENGTH CHARACTERISTICS}

\subsection{Material and Experimental Procedure}

The material tested was a gas pressure sintered silicon nitride designated EC-142, produced by NGK Spark Plug Co. Ltd. Its bulk density was $3.23 \mathrm{Mg} / \mathrm{m}^{3}$, and mechanical properties of the material were as follows. The fracture toughness $K_{\text {IC }}$ obtained by the method specified in the Japanese Industrial Standard (JIS R1607) was 6.0MPa $\sqrt{\mathrm{m}}$, Vickers hardness measured under an indentation load of $290 \mathrm{kN}$ was 1500MPa, and Young's modulus and Poisson's ratio were $320 \mathrm{GPa}$ and 0.27 , respectively.

All specimens were cut out from sintered plates of $100 \times 100 \mathrm{~mm}$ with a thickness of $10 \mathrm{~mm}$, and ground by using \#400-mesh diamond wheels. Smooth specimens were machined into two types with distinct dimensions of $4 \times 4 \times 40 \mathrm{~mm}$ and $4 \times 6 \times 40 \mathrm{~mm}$. Specimens ground longitudinally, i.e., in the direction parallel to tensile stress direction on the surface of tensile side, will be designated $\mathrm{S}-44 \mathrm{P}$ for the type with a cross section of $4 \times 4 \mathrm{~mm}$, and S-46P for that of $4 \times 6 \mathrm{~mm}$. Another group of specimens was prepared so that the grinding direction coincided with the direction of machining a notch in a notched specimen. These specimens with cross sections of $4 \times 4 \mathrm{~mm}$ and $4 \times 6 \mathrm{~mm}$, which were ground transversely, i.e., in the direction vertical to tensile stress direction on the surface of tensile side, will be called S-44V and S-46V, respectively.

Three types of notched specimens as shown in Fig.1 were prepared. Notched specimens of $4 \times 6 \times 40 \mathrm{~mm}$ with a straight notch of $1 \mathrm{~mm}$ in width and $3 \mathrm{~mm}$ in depth, $4 \times 4 \times 40 \mathrm{~mm}$ with a semi-circular notch of $1 \mathrm{~mm}$ root radius, and $4 \times 6 \times 40 \mathrm{~mm}$ with that of $3 \mathrm{~mm}$ root radius are designated $\mathrm{N}-\mathrm{ST}, \mathrm{N}-\mathrm{R} 1$ and $\mathrm{N}-\mathrm{R} 3$, respectively. After grinding the tensile side surface longitudinally, the notch root in each type of specimen was machined in the transverse direction due to a restric- 
tion in setting a grinding wheel. Also note that the machining of notches by using specially shaped wheels was more rough than that in the S-44V and S-46V type specimens, though they were similarly ground in the transverse direction of specimen. The stress concentration factor by a finite element analysis was 2.82 for N-ST, 1.71 for N-R1 and 1.26 for N-R3.

All bending tests were conducted under four-point bending with an outer span length of $30 \mathrm{~mm}$ and an inner span length of $10 \mathrm{~mm}$, in an ambient atmosphere of $289 \pm 0.5 \mathrm{~K}$ in temperature and $69 \pm 1 \%$ in relative humidity. Loading rate was controlled so that the rate of the maximum tensile stress in a specimen might be about $100 \mathrm{MPa} / \mathrm{s}$. The maximum tensile stress in notch root was controlled in the notched specimens. The bending strength $\sigma_{\mathrm{f}}$ of a specimen was evaluated as the maximum stress monitored at its fracture.
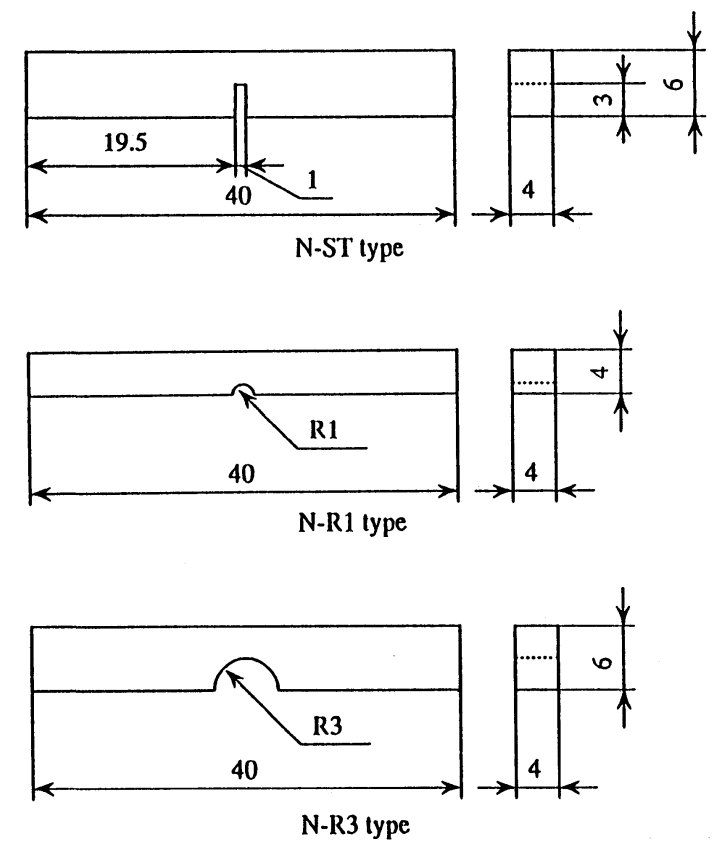

Fig.1. Dimensions of notched specimens (in $\mathrm{mm}$ ).

\subsection{Experimental Result and Discussion}

Cumulative probability $F\left(\sigma_{\mathrm{f}}\right)$ of bending strength was calculated by median ranking method. Figures 2 and 3 show the strength distributions in smooth and notched specimens plotted on Weibull probability paper. For reference, the broken line in Fig.2 presents the strength distribution obtained in a round robin test of the same material [16], including the result by one of the authors and his colleague [17], by using specimens of JIS type specified in JIS R1601. The JIS type specimens with dimensions of $4 \times 3 \times 40 \mathrm{~mm}$ were ground longitudinally, and referred to as "silicon nitride RF" in the literature [16]. This type of specimen is hereinafter called S-JIS. Each straight line in both the figures shows the strength distribution fitted by the two-parameter Weibull distribution function. In Fig.2, the distribution for the S-JIS type specimen is located in the highest strength region. It is difficult, however, to see an obvious trend in strength distribu- tions for other types of specimens. On the other hand, as seen in Fig.3, the distributions for notched specimens are found to shift toward the higher strength regime in the order of N-R3, N-R1 and N-ST type.

Statistical parameters of bending strength are summarized in Table 1. The shape and scale parameters in the table were obtained for the distribution fitted by a Weibull distribution function with two parameters. In particular, the shape parameter $m$ depends on whether a specimen has a notch or not, i.e., the $m$ value of about 26 in notched specimens is significantly large compared with that around 10 in smooth specimens. This implies that a relative scatter of strength in notched specimens is less than that in smooth specimens. The same tendency on strength dispersion is also confirmed by a difference in the coefficient of variation between smooth and notched specimens. No influence of grinding direction on the mean strength $\mu$ is seen in the S-46 type specimen, though the mean strength of the S-44 type specimen ground transversely is lower than that of the same type specimen ground longitudinally. Considering that the cross section area of specimen increases in the order of S-JIS, S-44 and S-46 type, the mean strength in smooth specimens ground longitudinally tends to decrease slightly with increasing the specimen size.

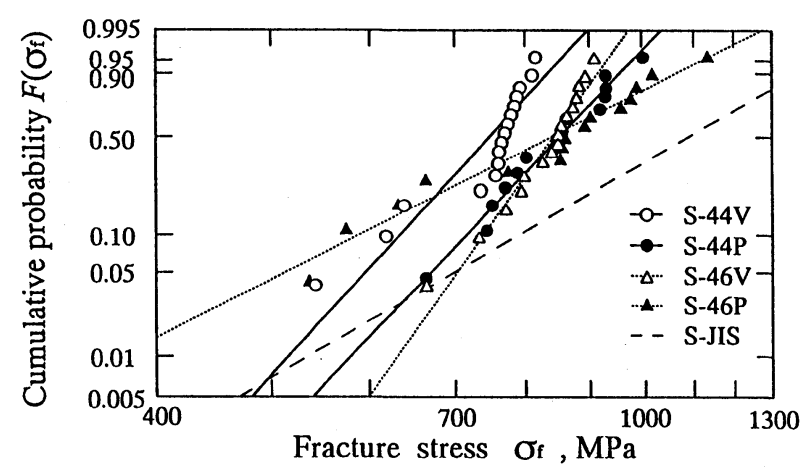

Fig.2. Strength distribution in smooth specimens.

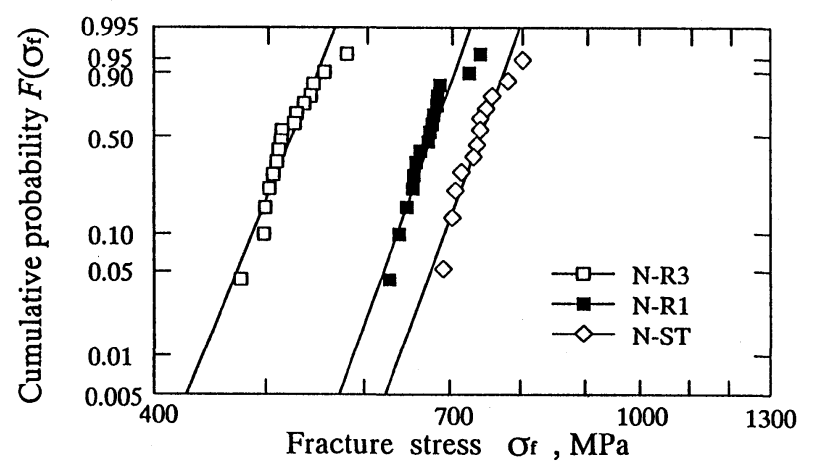

Fig.3. Strength distribution in notched specimens.

A remarkable difference in the morphology of fracture surface was observed between smooth and notched specimens. The typical aspect in ceramics, indicating mirror or mist and hackle around an inherent flaw, was seen in smooth specimens independently 
Toshihiko HOSHIDE, Hirokazu SANO and Hiroyuki HONDA

Table 1. Statistics of strength in experiment.

\begin{tabular}{c|c|c|c|c|c|c}
\hline \multicolumn{2}{c|}{ Specimen geometry } & $\begin{array}{c}\text { Mean } \\
\text { strength } \\
\mu, \mathrm{MPa}\end{array}$ & $\begin{array}{c}\text { Standard } \\
\text { deviation, } \\
\text { MPa }\end{array}$ & $\begin{array}{c}\text { Coefficient } \\
\text { of } \\
\text { variation }\end{array}$ & $\begin{array}{c}\text { Shape } \\
\text { parameter } \\
m\end{array}$ & $\begin{array}{c}\text { Scale } \\
\text { parameter, } \\
\text { MPa }\end{array}$ \\
\hline \hline \multirow{5}{*}{ Smooth } & S-JIS & 942 & 139 & 0.148 & 8.0 & 1000 \\
& S-44P & 858 & 91 & 0.106 & 10.4 & 898 \\
& S-44V & 752 & 77 & 0.102 & 10.8 & 786 \\
& S-46P & 853 & 176 & 0.206 & 5.0 & 927 \\
& S-46V & 844 & 65 & 0.077 & 14.1 & 874 \\
\hline \multirow{5}{*}{ Notched } & N-ST & 743 & 31 & 0.042 & 27.0 & 757 \\
& N-R1 & 678 & 30 & 0.044 & 27.6 & 691 \\
& N-R3 & 519 & 25 & 0.048 & 24.8 & 530 \\
\hline
\end{tabular}

of their grinding directions. In notched specimens, however, a flat and featureless fracture surface was observed. The feature of fracture surface in notched specimens is considered to be caused by the fracture initiating from a transverse edge-crack formed along the notch root due to heavier machining of notch as noted in the previous section. This observation suggests that the flaw morphology in smooth specimens differs from that in notched ones.

\section{INFLUENCE OF SPECIMEN GEOME- TRY ON STRENGTH}

\subsection{Effective Volume Theory}

The effective volume has been applied to explain the strength characteristics depending on the specimen geometry and/or the loading mode [14]. In this section, the concept, from which the effective volume was derived, will be briefly outlined before correlating the experimental results with the effective volume, because it is important to refer to the concept in the discussion on the validity of the effective volume.

The Weibull theory [15], which is basic to the effective volume concept, and the related fundamental equations are first described. Weibull expressed the failure probability $F$ of a homogeneous material with a volume $V$ under an arbitrary stress state as

$$
F=1-\exp \left(-\int_{V} n(\sigma) \mathrm{d} v\right)
$$

where the stress $\sigma$ in $n(\sigma)$ depends on the position of infinitesimally small volume $\mathrm{d} v$ in the material. He also discussed the physical meaning of the function $n(\sigma)$, and suggested that $n(\sigma)$ is a function associated with the density of flaws, from which fracture can be initiated at a stress lower than $\sigma$. Weibull proposed a function type of $n(\sigma)$ as the following expression to explain experimental results concerning strength reported at that time.

$$
n(\sigma)=\left(\frac{\sigma}{\sigma_{0}}\right)^{m},
$$

where $\sigma_{0}$ is a material constant and $m$ is later referred to as the shape parameter in the two-parameter model of Weibull distribution function. It should be noted that there may be a limitation in the above interpretation of $n(\sigma)$ by Weibull, though he did not point out the limitation in his paper. When reducing $\mathrm{d} v$ infinitesimally small in the integral operation in Eq.(1), the number of flaws must not be constant or there may be no flaws in such an infinitesimally small $\mathrm{d} v$ because the size of any flaw is finite. Substitution of Eq.(2) into Eq.(1) yields

$$
F=1-\exp \left\{-\int_{V}\left(\frac{\sigma}{\sigma_{0}}\right)^{m} \mathrm{~d} v\right\} .
$$

Davies [13] derived the effective volume from the above fundamental formulations in the Weibull theory. Using a representative stress $\sigma_{R}$ defined in a component, he introduced the effective volume $V_{\mathrm{E}}$ as

$$
V_{\mathrm{E}}=\int_{V}\left(\frac{\sigma}{\sigma_{\mathrm{R}}}\right)^{m} \mathrm{~d} v
$$

The maximum stress is usually adopted as $\sigma_{\mathrm{R}}$. Since it is reasonable to consider that no fracture occurs in the region where the stress is compressive or zero, the volume integration in the region of $\sigma \leq 0$ may be excluded in Eq.(4). Using Eq.(4), Eq.(3) reduces to

$$
F=1-\exp \left\{-\left(\frac{\sigma_{\mathrm{R}}}{\sigma_{\mathrm{o}}}\right)^{m} V_{\mathrm{E}}\right\} .
$$

According to the above equation, Davies investigated the dependency of strength on the specimen size and the loading mode in a brittle material. The representative stress $\sigma_{\mathrm{R}}$ in a component is used as its fracture strength. If the mean values of strength for components with the effective volumes of $V_{\mathrm{E} 1}$ and $V_{\mathrm{E} 2}$ are expressed as $\mu_{1}$ and $\mu_{2}$ respectively, the following relation is given from Eq.(5) [13].

$$
\frac{\mu_{1}}{\mu_{2}}=\left(\frac{V_{\mathrm{E} 2}}{V_{\mathrm{E} 1}}\right)^{1 / m} .
$$

\subsection{Strength and Effective Volume}

For a smooth specimen under four-point bending with the same outer span to inner span ratio of 3 as in the present loading mode, the effective volume is 
theoretically calculated from Eq.(4) as

$$
V_{\mathrm{E}}=V \frac{m+3}{6(m+1)^{2}},
$$

where $V$ is the whole volume within the outside span of the specimen. On the other hand, the effective volume of a notched specimen is evaluated as Eq.(8) by using a result given in a finite element analysis, where elements of triangle type with constant strain are used for the mesh of notched specimen.

$$
V_{\mathrm{E}}=\sum_{i}\left(\frac{\sigma_{i}}{\sigma_{\max }}\right)^{m} V_{i},
$$

where $\sigma_{i}$ in the $i$-th element in the mesh of notched specimen and $\sigma_{\max }$ are the normal stress and the maximum stress calculated by the finite element analysis, respectively. The volume of the $i$-th element, $V_{i}$, is given by multiplying the area of the element by its thickness. The summation with respect to $i$ in Eq. (8) is made only for elements where the normal stress in the longitudinal direction of a specimen is positive, because no fracture is expected to occur in elements with negative stress. Although a direct verification on the validity of the evaluation using Eq. (8) cannot be made for the notched specimens for lack of theoretical stress distribution in them, the validity is verified for smooth specimens by confirming the difference within $\pm 5 \%$ between the theoretical calculation by Eq.(7) and the result evaluated by Eq.(8).

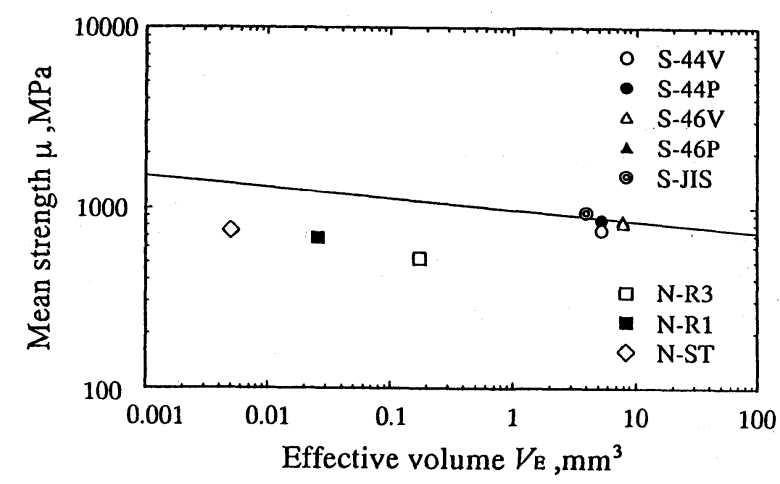

Fig.4. Relation between mean strength and effective volume in experiment.

In Fig.4, the mean strength $\mu$ for each type of specimen is correlated with the effective volume $V_{\mathrm{E}}$ evaluated by using Eqs.(7) and (8) for the corresponding specimen type. The mean value of $m$ in the Weibull distribution function fitted by the twoparameter model was adopted in calculating $V_{\mathrm{E}}$, because $m$ value for each type of specimen was different each other as mentioned previously. The straight line in Fig. 4 presents the relation of Eq.(6) passing the data point for the $\mathrm{S}-46 \mathrm{~V}$ type specimen with the $m$ value close to the mean of $m$ values obtained for all specimen types. Although the data for smooth specimens can be almost expressed by the relation of Eq.(6), those for the notched specimens shift toward the lower strength side from the relation. The difference between the relations in smooth and notched specimens is primarily attributed to the fact that the morphology of fracture origins in smooth specimens differs from that in notched specimens as described in Section 2.2. Another reason for the difference may be associated with a wide variation in $m$ value observed experimentally. A consistent $m$ value is found to be given by using more specimens $[12,18]$, though the number of specimens was restricted due to the preparation from the same lot of the material in this work.

\section{ANALYSIS OF STRENGTH DEPENDING ON SPECIMEN GEOMETRY BY NUMERI- CAL SIMULATION}

\subsection{Procedure of Simulation}

In the present analysis, flaws distributed in a specimen were modeled as circular, semi-circular or quarter-elliptical cracks. Cracks in a specimen were randomly located only in the region of cross section subjected to tensile stress. The stress intensity factor $K$ of opening mode for each crack in an individual specimen was calculated by taking account of the crack shape and the stress distribution generated in the specimen. The failure of each specimen was assumed to be dominated by the crack with the maximum stress intensity factor $K_{\max }$ in the specimen. The fracture stress of a specimen was decided as the applied stress when $K_{\max }$ in the specimen just reached the fracture toughness $K_{\mathrm{IC}}$.

The location and the size of a crack were given independently by using a series of quasi-uniform random numbers. Two Weibull distribution functions of crack size were employed to describe the distribution of inherent flaws formed during the sintering process, and of grinding-induced flaws, respectively. Each Weibull distribution function was based on the threeparameter model. Crack size distribution and crack density were determined by trial and error so that the resultant strength distribution for the S-JIS type specimen coincided with the experimental one. The size distribution was truncated at the maximum value so that the physical meaning was not lost. The density of inherent cracks was defined as the number of cracks per unit volume, though the density of cracks caused by grinding was given as the number of cracks per unit surface area because of the damage restricted on the ground surface. Since corner cracks and surface cracks were not classified in a two-dimensional analysis, the ratio of corner cracks to surface ones was given empirically according to the grinding conditions. A more detailed procedure is described elsewhere [19].

It has been known $[17,19-21]$ that the failure criterion under the constant fracture toughness cannot be directly applied to evaluate the failure of ceramics when the fracture is initiated from such a small flaw as modeled above. The flaw boundary layer model [19] had been proposed as one of models to explain the flaw size dependency of strength in ceramics, and the model was also applied to the present simulation. In the model, it is assumed that a weaker layer com- 
Toshihiko HoSHIDE, Hirokazu SANO and Hiroyuki HoNDA

Table 2. Parameters used in simulation.

\begin{tabular}{c|c|c|c|c|c|c|c}
\hline & Density & Shape & $\begin{array}{c}\text { Location } \\
\text { parameter, } \\
\mu \mathrm{m}\end{array}$ & $\begin{array}{c}\text { Scale } \\
\text { parameter, } \\
\mu \mathrm{m}\end{array}$ & $\begin{array}{c}\text { Truncated } \\
\text { maximum } \\
\text { length, } \mu \mathrm{m}\end{array}$ & $\begin{array}{c}\text { Fraction of corner } \\
\text { cracks to surface } \\
\text { cracks, } \%\end{array}$ & $\begin{array}{c}\text { Flaw } \\
\text { boundary } \\
\text { layer, } \mu \mathrm{m}\end{array}$ \\
\hline \hline Inherent & $1.5 / \mathrm{mm}^{3}$ & 1.6 & 2.5 & 9.0 & 50 & 10 & 6.0 \\
cracks & parameter & 1.5 & 12 & 15 & 150 & 10 & 6.0 \\
\hline $\begin{array}{c}\text { Grinding- } \\
\text { induced } \\
\text { cracks }\end{array}$ & $0.125 / \mathrm{mm}^{2}$ & 1.5 & & & & & \\
\hline
\end{tabular}

Table 3. Strength parameters obtained in simulation.

\begin{tabular}{c|c|c|c|c|c|c}
\hline \multicolumn{2}{c|}{$\begin{array}{c}\text { Specimen geometry, mm } \\
W: \text { width, } t \text { : thickness, } \\
S: \text { inner span, } R \text { : radius }\end{array}$} & $\begin{array}{c}\text { Mean } \\
\text { strength } \\
\mu, \mathrm{MPa}\end{array}$ & $\begin{array}{c}\text { Standard } \\
\text { deviation, } \\
\text { MPa }\end{array}$ & $\begin{array}{c}\text { Coefficient } \\
\text { of } \\
\text { variation }\end{array}$ & $\begin{array}{c}\text { Shape } \\
\text { parameter } \\
m\end{array}$ & $\begin{array}{c}\text { Scale } \\
\text { parameter, } \\
\mathrm{MPa}\end{array}$ \\
\hline \hline \multirow{6}{*}{ Smooth } & $2.0 W \times 1.5 t(5 S)$ & 1269 & 267 & 0.210 & 5.651 & 1369 \\
& $2.0 W \times 2.0 t(10 S)$ & 1103 & 193 & 0.175 & 6.782 & 1179 \\
& $4.0 W \times 3.0 t(10 S)$ & 953 & 134 & 0.141 & 8.454 & 1008 \\
& $4.0 W \times 4.0 t(10 S)$ & 967 & 126 & 0.130 & 9.255 & 1018 \\
& $4.0 W \times 6.0 t(10 S)$ & 940 & 128 & 0.136 & 8.538 & 994 \\
& $8.0 W \times 8.0 t(10 S)$ & 890 & 110 & 0.124 & 9.084 & 939 \\
& $8.0 W \times 6.0 t(20 S)$ & 814 & 90.7 & 0.111 & 10.84 & 852 \\
\hline \multirow{6}{*}{ Notched } & straight (10S) & 3174 & 688 & 0.217 & 6.266 & 3396 \\
& semi-circular $R 1(10 S)$ & 1931 & 444 & 0.230 & 5.337 & 2089 \\
& semi-circular $R 3(10 S)$ & 1513 & 272 & 0.180 & 7.179 & 1611 \\
\hline
\end{tabular}

pared with the matrix material exists around a flaw and a constant thickness $\delta$ of the layer is added to the original size of the flaw in calculating $K$ as the first approximation. The flaw boundary layer of $6 \mu \mathrm{m}$ was found to be adequate for this material by trial and error.

The parameters used in the simulation are summarized in Table 2.

\subsection{Simulated Result and Discussion}

A Monte Carlo simulation was carried out for the same shapes of notched specimens as in the experiment, though smooth specimens with other dimensions different from those used in the experiment were included in the simulation. The same characteristics of crack distribution were assumed in these specimens. Using fifty series of random numbers, fifty trials were carried out for a specified specimen geometry by creating fifty different configurations of geometrical crack distribution. This resulted in fifty strength data for the specimen.

Statistical parameters in strength distributions for various specimens obtained by the simulation are listed in Table 3 . As seen in the table, the mean strength $\mu$ of smooth specimen decreases with increasing the specimen volume, as expected from Eq.(6). It should be noted that the variation in the shape parameter $m$ obtained in the simulation is not so large in comparison with that observed in the experiment; the ratio of the maximum to minimum $m$ value is about 2 in the simulation but larger than 5 in the experiment.
Figure 5 shows the relationship of the mean strength to the effective volume calculated by using the mean value of $m$ for each specimen in the simulation, just as in Section 3.2. The straight line in the figure presents the relation of Eq.(6) passing the data point for the JIS type specimen with $m$ value which is almost close to the mean value of $m$. In this case, all data including those for notched specimens can be almost uniquely correlated by Eq.(6) differently from the experimental result as shown in Fig.4. The simulated result reveals that the effective volume is efficient to explain the dependence of the strength on the specimen geometry in a material with the same characteristics of crack distribution.

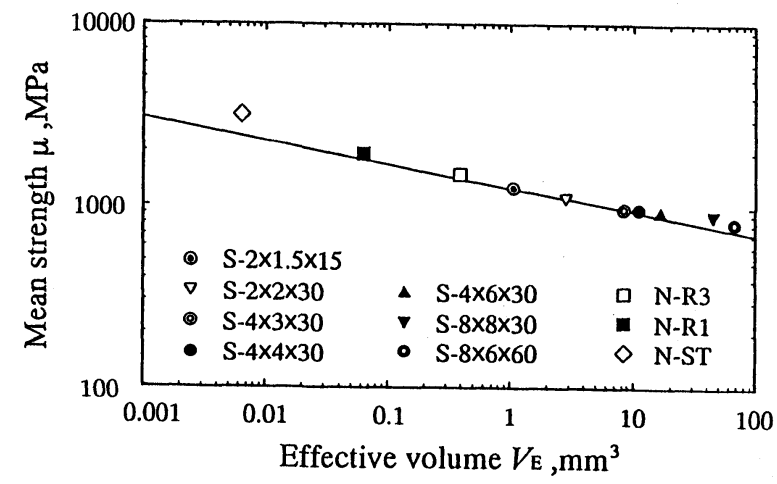

Fig.5. Simulated relation between mean strength and effective volume. 
Table 4. Strength parameters obtained in simulation for a material with lower crack density.

\begin{tabular}{c|c|c|c|c|c|c}
\hline \multicolumn{2}{c}{$\begin{array}{c}\text { Specimen geometry, mm } \\
W: \text { width, } t \text { : thickness, } \\
S: \text { inner span, } R: \text { radius }\end{array}$} & $\begin{array}{c}\text { Mean } \\
\text { strength } \\
\mu, \mathrm{MPa}\end{array}$ & $\begin{array}{c}\text { Standard } \\
\text { deviation, } \\
\mathrm{MPa}\end{array}$ & $\begin{array}{c}\text { Coefficient } \\
\text { of } \\
\text { variation }\end{array}$ & $\begin{array}{c}\text { Shape } \\
\text { parameter } \\
m\end{array}$ & $\begin{array}{c}\text { Scale } \\
\text { parameter, } \\
\text { MPa }\end{array}$ \\
\hline \hline \multirow{6}{*}{ Smooth } & $2.0 W \times 1.5 t(5 S)$ & 4069 & 4865 & 1.196 & 2.100 & 3893 \\
& $2.0 W \times 2.0 t(10 S)$ & 1562 & 347 & 0.222 & 5.571 & 1685 \\
& $4.0 W \times 3.0 t(10 S)$ & 1354 & 258 & 0.191 & 6.476 & 1450 \\
& $4.0 W \times 4.0 t(10 S)$ & 1299 & 219 & 0.169 & 6.734 & 1390 \\
& $4.0 W \times 6.0 t(10 S)$ & 1231 & 181 & 0.147 & 8.411 & 1302 \\
& $8.0 W \times 8.0 t(10 S)$ & 1150 & 125 & 0.109 & 10.92 & 1203 \\
& $8.0 W \times 6.0 t(20 S)$ & 1053 & 130 & 0.123 & 9.478 & 1108 \\
\hline \multirow{6}{*}{ Notched } & straight $(10 S)$ & 8383 & 3676 & 0.439 & 2.584 & 9392 \\
& semi-circular $R 1(10 S)$ & 3490 & 985 & 0.282 & 3.978 & 3845 \\
& semi-circular $R 3(10 S)$ & 2649 & 1134 & 0.428 & 3.219 & 2905 \\
\hline
\end{tabular}

As noted in Section 3.1, the effective volume was derived from the Weibull theory based on the primitive assumption, in which any infinitesimally small volume in a material has the same flaw distribution as in the bulk material. Next, it is discussed whether the effective volume can explain the effect of the specimen geometry on strength when the number of flaws in a material decreases extremely. The simulation was carried out in the case where only the flaw density was set to one-tenth of that in Table 2 but the other characteristics in the flaw distribution were kept. Table 4 indicates the simulated result, and shows a much larger scatter in strength compared with the strength dispersion in the previous simulation in Table 3.

Figure 6 presents the relation between the mean strength and the effective volume calculated by using the mean value of $m$ obtained in the simulation. The straight line in the figure is the relation of Eq.(6) for the S-46 specimen with $m$ value which is almost close to the mean of $m$. No unique correlation by Eq.(6) is found in Fig. 6 differently in Fig.5. This is caused by the limitation in the applicability of Eq.(4), resulting from invalid assumption in the Weibull theory, i.e., the same flaw distribution as in a bulk material cannot exist in any infinitesimally small volume when the flaw density is extremely low. The result also suggests that the Weibull distribution is inadequate to be used as an asymptotic distribution in this situation.

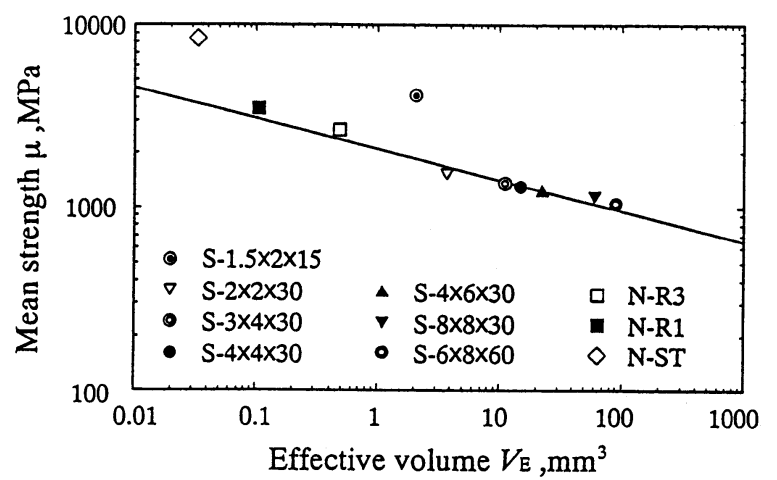

Fig.6. Simulated relation between mean strength and effective volume in case of lower crack density.

\section{CONCLUSION}

In this study, the influence of the size and/or notch shape of specimen on the strength was investigated based on experimental results using a gas pressure sintered silicon nitride and a Monte Carlo simulation.

Strength characteristics of smooth specimens of different size and of notched specimens with distinct notch shapes were examined under four-point bending. The mean strength in smooth specimens, which showed no significant influence of difference in grinding direction on strength, was almost able to be correlated with the effective volume. Although the mean strength of notched specimens decreased compared with that of smooth specimens, the dispersion of strength in notched specimens was found to be smaller than that in smooth specimens. All failure of notched specimens was caused by the grinding-induced crack, while fracture initiated from an inherent flaw was observed in almost all of smooth specimens. No unique correlation of the strength with the effective volume was primarily attributed to such a difference in flaw morphology between smooth and notched specimens.

A Monte Carlo simulation was done by assuming the distribution characteristics of cracks in a material so that the strength characteristics in the JIS type specimen could be fitted appropriately. The simulation revealed that the effect of the specimen geometry on the strength was explained by using the effective volume. When the flaw density was extremely low in a material, however, the effective volume was clarified to be inefficient because of a failure of the primitive assumption in the Weibull theory.

Acknowledgments - The authors are much indebted to Professor Tatsuo Inoue, Kyoto University, for valuable discussion. Thanks are also due to the Committee on Fatigue, the Society of Materials Science, Japan, for providing the material.

\section{REFERENCES}

1. R.L. Jones and D.J. Rowcliffe, Ceram. Bull., 58 (1979) 836. 
2. D.K. Shetty, A.R. Rosenfield, G.K. Bansal and W.H. Duckworth, J. Amer. Ceram. Soc., 64 (1981) 1.

3. G.K. Bansal, W.H. Duckworth and D.E. Niesz, J. Amer. Ceram. Soc., 59 (1982) 472.

4. Y. Katayama and Y. Hattori, J. Amer. Ceram. Soc., 65 (1982) C-164.

5. K. Matsusue, K. Takahara and R. Hashimoto, YogyoKyokai-Shi, 90 (1982) 168.

6. K. Matsusue, K. Takahara and R. Hashimoto, YogyoKyokai-Shi, 90 (1982) 280

7. D.M. Neal and E.M. Lenoe, Fract. Mech. Ceram., 5 (1983) 387.

8. H. Fessler, D.C. Fricker and D.J. Godfrey, CeramPerform. Appl., 3 (1983) 705.

9. D.K. Shetty, A.R. Rosenfield and W.H. Duckworth, ASTM STP 844 (1984) 57.

10. T. Yamada and T. Hoshide, Proc. ICOSSAR '85, II (1985) 441.

11. T. Soma, M. Matsui and I. Oda, Non-Oxide Technical and Engineering Ceramics (ed. by S. Hampshire), Elsevier Appl. Sci., London (1986) 361.
12. B.A. Kschinka, S. Perrella, H. Nguyen and R.C. Bradt, J. Amer. Ceram. Soc., 69 (1986) 467.

13. D.G.S. Davies, Proc. Br. Ceram. Soc., 22 (1973) 429.

14. For example, R.W. Davidge, Mechanical Behaviour of Ceramics, Cambridge Univ. Press (1979) p.138.

15. W. Weibull, Ing. Vetenkaps Akad. Handl. (Proc. Roy. Swedish Inst. Eng. Res., Stockholm), No.151 (1939).

16. Working-Group on Reference Ceramic Materials, SubCommittee on Ceramic Strength, Committee on Fatigue, JSMS, J. Soc. Mater. Sci., Japan, 44 (1995) 249 .

17. T. Hoshide and M. Masuda, Mater. Sci. Res. Int., 1 (1995) 108.

18. S.G. Seshadri and M. Srinivasan, Trans. ASME, J. Eng. Mater. Tech., 105 (1983) 219.

19. T. Hoshide and T. Inoue, Eng. Fract. Mech., 38 (1991) 307.

20. T. Hoshide, H. Furuya, Y. Nagase and T. Yamada, Int. J. Fract., 26 (1984) 229.

21. T. Hoshide, Eng. Fract. Mech., 44 (1993) 403. 